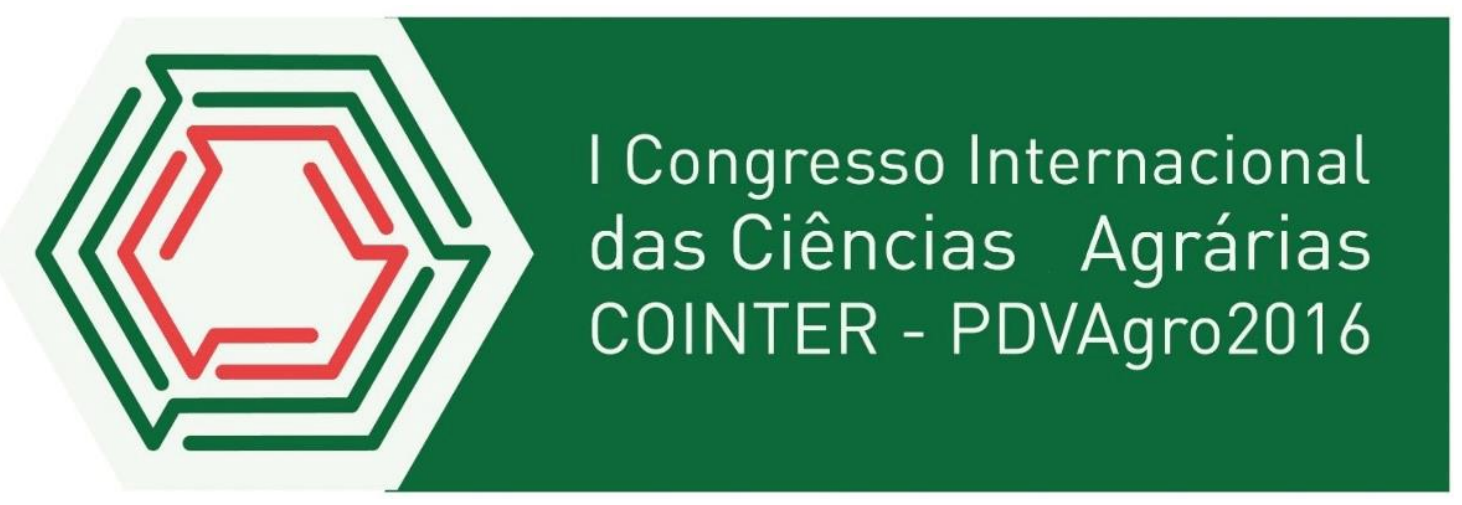

\title{
PRODUÇÃO DE MUDAS DE PIMENTÃO ADUBADO COM BIOFERTILIANTE LÍQUIDO E SUBSTRATOS EM AMBIENTE PROTEGIDO
}

Apresentação: Pôster

Dayara Cezário Da Silva ${ }^{1}$; Daniel Da Silva Dantas ${ }^{1}$; Daniel Da Silva Ferreira ${ }^{1}$; Sebastião De Oliveira Mesquita Sobrinho ${ }^{1}$; Raimundo Andrade ${ }^{2}$

${ }^{1}$ Graduandos do Curso de Ciências Agrárias/DAE/UEPB, E-mail: dayara-silva12@hotmail.com

${ }^{2}$ Prof. Doutor/Pesquisador DAE/CCHA/UEPB, E-mail raimundo andrade@ uepb.edu.br

\section{Introdução}

Para produzir mais foi imprescindível criar condições mais propícias para o desenvolvimento das plantas surgindo, então, os adubos, os defensivos, o melhoramento genético, o manejo de solo e a irrigação, dentre outros; além disso, havia o problema da sazonalidade climática, que permitia o cultivo apenas em alguns períodos do ano (RESENDE e GONÇALVES, 2004).

Os biofertilizantes são compostos bioativos, resíduo final da fermentação de compostos orgânicos, contendo células vivas ou latentes de microorganismos (bactérias, leveduras, algas e fungos filamentosos) e por seus metabólitos, além de quelatos organo-minerais. Essa tecnologia de processo vem revolucionando a agricultura e encontra fundamentos na teoria da trofobiose, desenvolvida pelo frances Francis Chaboussou em meados século passado e na agroecologia (CHABOUSSOU, 1985).

A utilização de recipientes com substratos em substituição ao uso de solo, na formação de mudas, tem proporcionado melhorias substanciais na qualidade destas (SMIDERLE et al., 2001; RAMOS et al., 2002), sendo os substratos comerciais considerados de melhor qualidade, podendo o viveirista e/ou o horticultor 
desenvolverem seu próprio substrato com menor custo e utilizando material mais próximo da propriedade.

Diante o exposto, objetivou-se analisar o efeito de diferentes dosagens de biofertilizante comum e composição de substratos orgânicos sob formas de adubação em sistemas agroecológicos no crescimento de mudas de pimentão em ambiente protegido.

\section{Fundamentação Teórica}

O pimentão, Capsicum annuum (Solanaceae), é uma hortaliça de grande importância socioeconômica no Brasil, sendo comercializado como fruto verde, vermelho, amarelo, laranja, creme e roxo. Seu valor nutritivo, para consumo ao natural, deve-se, em grande parte, à presença de vitaminas, especialmente a vitamina C (CNPH, 2001).

Um substrato influi, por meio de sua fase sólida, na manutenção do sistema radicular da planta; no suprimento de água e nutrientes pela fase líquida; no oxigênio e transporte de carbono entre as raízes; e no ar externo pela fase gasosa (MINAMI e PUCHALA, 2000). Assim, além das propriedades químicas e físico-hídricas adequadas, para melhorarem a relação água/ar e a disponibilidade de nutrientes (FERNANDES e CORÁ, 2000), os substratos devem estar livres de fitopatógenos e sementes de plantas indesejáveis, bem como serem compostos por materiais de baixo custo, fácil aquisição (FACHINELLO et al., 2005), longa durabilidade e recicláveis, ou ainda desenvolverem métodos para reaproveitamento e melhoria das condições químicas e físicas do solo (SASSAKI, 1997).

De acordo com Santos (2001), biofertilizante é a designação dada ao efluente líquido obtido da fermentação metanogênica da matéria orgânica e água; enquanto Alves et al. (2001), o definem como resíduo final da fermentação de compostos orgânicos que contêm células vivas ou latentes de microrganismos (bactérias, leveduras, algas e fungos filamentosos) e por seus metabólicos, além de quelatos organominerais.

\section{Metodologia}

$\mathrm{O}$ ensaio foi realizado em ambiente protegido no setor de viveiricultura, na Escola Agrotécnica do Cajueiro, pertencente a Universidade Estadual da Paraíba, 
distando $02 \mathrm{~km}$ da sede do município de Catolé do Rocha/PB, cujo as coordenadas geográficas são $\left(6^{0} 20^{\prime} 38^{\prime}\right.$ ' de latitude sul; $37^{0} 44^{\prime} 48^{\prime \prime}$ a oeste do meridiano de Greenwich com uma altitude de $275 \mathrm{~m}$ acima do nível do mar, o referido município está situado na região semiárida do Nordeste brasileiro, no Noroeste do Estado da Paraíba.

O delineamento experimental adotado foi o inteiramente casualizado (DIC), com quatro repetições e 64 plantas experimentais, em esquema fatorial de 4 x 4 totalizando 16 tratamentos. Os tratamentos foram referentes a quatro doses de biofertilizante via solo $\left[\left(\mathrm{D}_{1}=0,0(\mathrm{~mL} /\right.\right.$ planta/vez $) ; \mathrm{D}_{2}=5,0(\mathrm{~mL} /$ planta/vez $) ; \mathrm{D}_{3}=10,0(\mathrm{~mL} /$ planta/vez$) ;$ $D_{4}=15,0(\mathrm{~mL} /$ planta/vez $\left.\left.)\right)\right]$, e quatro substratos $\left(S_{1}=100 \%\right.$ de solo; $S_{2}=50 \%$ de solo + $50 \%$ de húmus; $\mathrm{S}_{3}=75 \%$ de solo $+25 \%$ de húmus e $\mathrm{S}_{4}=75 \%$ de húmus $+25 \%$ de solo) no crescimento de plantas de pimentão orgânico.

\section{Resultados e Discussão}

O comportamento do número de folhas de plantas de pimentão orgânico, em relação às dosagens de biofertilizante comum, teve um comportamento linear positivo (Figura 01). Observa-se que o número de folhas da planta foi aumentando de forma significativa com o incremento das doses de biofertilizante, tendo havido acréscimo de 0,2 folhas por aumento unitário das doses de biofertilizante em plantas de pimentão, atingindo, no nível máximo $\left(\mathrm{D}_{4}=15 \mathrm{ml} /\right.$ planta/vez, à média de 10 folhas. Conforme (Figura 02), não houve efeito significativo, apresentou similaridade no comportamento dos tratamentos em função da aplicação de diferentes substratos na cultura do pimentão no município de Catolé do Rocha/PB.

Figura 01. Aplicação de dosagens de biofertilizante no número de folhas de plantas de pimentão orgânico.
Figura 02. Aplicação de substratos no número de folhas de plantas de pimentão orgânico.
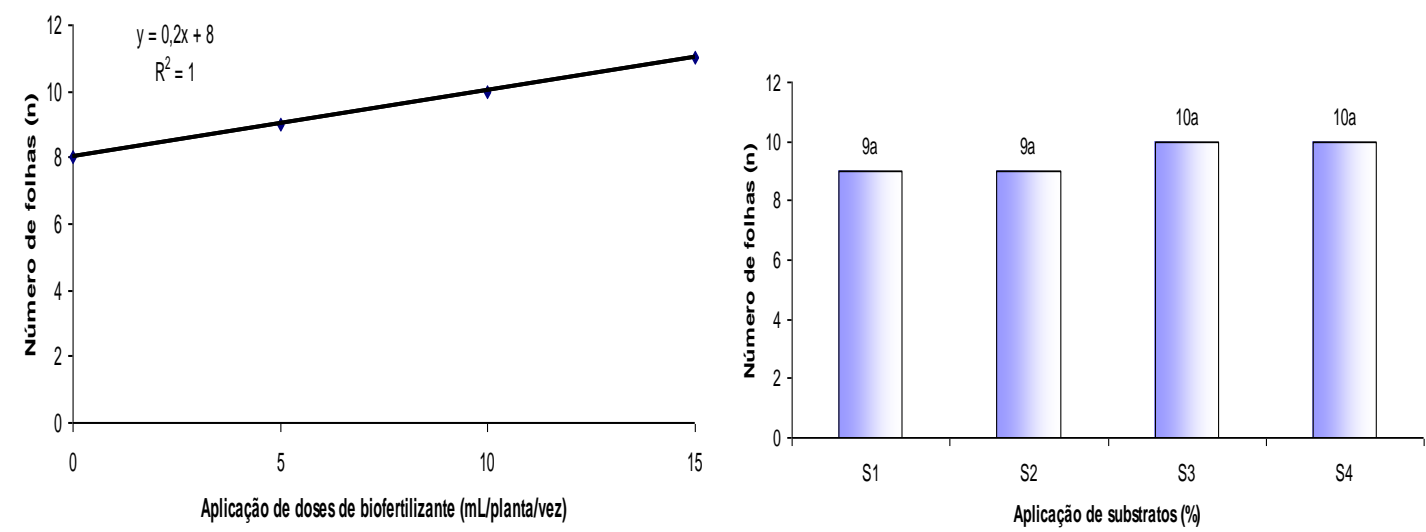
A evolução do crescimento de plantas de pimentão em altura, em relação às dosagens de biofertilizante comum, teve um comportamento linear crescente, com coeficiente de determinação de 0,99 (Figura 03). Observa-se que a altura da planta foi aumentando de forma significativa com o incremento das doses de biofertilizante, tendo havido acréscimo de $0,378 \mathrm{~cm}$ por aumento unitário das doses de biofertilizante em plantas de pimentão orgânico, atingindo, no nível máximo $\left(\mathrm{D}_{4}=15 \mathrm{ml} / \mathrm{planta} / \mathrm{vez}\right)$. Conforme (Figura 04), não houve efeito significativo, apresentou similaridade no comportamento dos tratamentos em função da aplicação de diferentes substratos na cultura do pimentão orgânico.

Figura 03. Aplicação de dosagens de biofertilizante plantas de pimentão orgânico.

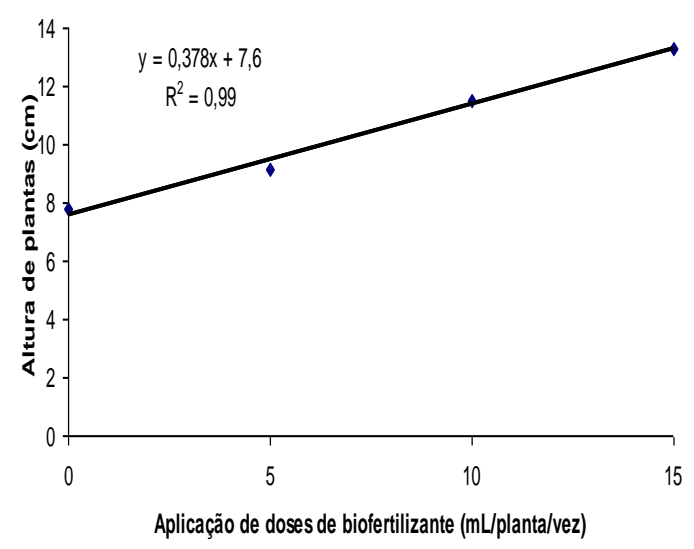

Figura 04. Aplicação de substratos na altura de plantas de pimentão orgânico.

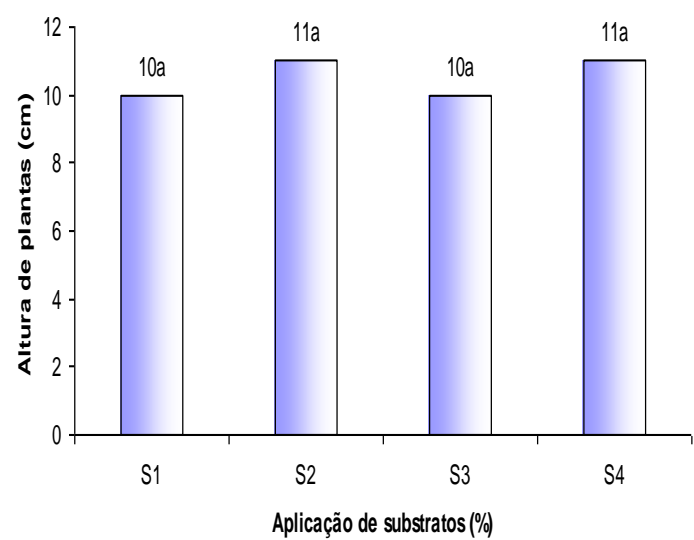

\section{Conclusões}

A dose $15 \mathrm{ml} /$ planta/vez de biofertilizante comum obteve o valor médio de 10 folhas por plantas de pimentão;

O valor máximo da altura de plantas de pimentão orgânico foi obtido com a dose de biofertilizante comum de $15 \mathrm{ml} /$ planta/vez $\left(\mathrm{D}_{4}\right)$;

Os substratos apresentaram similaridade nos diferentes tratamentos, não apresentando significância estatística em função do número de folhas e altura de plantas;

\section{Referências}

ALVES, S. B.; MEDEIROS, M. B.; TAMAI, M. A.; LOPES, R. B. Trofobiose e microrganismos na proteção de plantas: Biofertilizantes e entomopatógenos na citricultura orgânica. Biotecnologia Ciência \& Desenvolvimento, n.21, p.16-21, 2001. 
CHABOUSSOU, F. Les Plantes Malades des Pesticides. Paris: Editions Débard, 1985. $265 p$.

CNPH. Projeto Capsicum. Embrapa Hortaliças. 2001. Acessado em :10/12/2008.

FERNANDES, C.; CORÁ, J.E. Caracterização físico-hídrica de substratos utilizados no cultivo de hortaliçasHorticultura Brasileira, Brasília, v.18, Supl jul, p.471-473, 2000.

FACHINELlO, J.C. et. al. Propagação de plantas frutíferas. Brasília: Embrapa Informação Tecnológica, 2005. 221p.

MINAMI, K.; PUCHALA, B. Produção de mudas de hortaliças de alta qualidade. Horticultura Brasileira, Brasília, v.18, supl, p.162-163, 2000.

SANTOS, A. C. V. A ação múltipla do biofertilizante líquido como ferti fitoprotetor em lavouras comerciais. In: Hein, M. (org). Encontro de Processos de Proteção de Plantas: Controle ecológico de pragas e doenças, 1, 2001, Botucatu. Resumos... Botucatu: Agroecológica, 2001. p.91-96.

RAMOS, J.D. et al. Produção de mudas de plantas frutíferas por semente. Informe Agropecuário, Belo Horizonte, v.23, p.64-72, 2002.

Resende, L. V.; Gonçalves, W. M. Cultivo de hortaliças em estufas: Quando plantar? <http://www.snagricultura.org.br/artigos/ artitec-horicultura01.htm>. 10 Jun. 2004.

SASSAKI, O.K. Resultados preliminares da produção de hortaliças sem o uso de solo no Amazonas. Horticultura Brasileira, Brasília, v.15, p.165-169, 1997.

SMIDERLE O.J. et al. Produção de mudas de alface, pepino e pimentão em substratos combinando areia, solo e Plantmax ${ }^{\circledR}$. Horticultura Brasileira, Brasília, v.19, n.3, p.253-257, 2001. Disponível em: <http://www.scielo.br/scielo.php?script=sci_arttext\&pid=S010205362001000300022\&l 